\title{
Quality use of medicines in patients with chronic kidney disease
}

\author{
Ronald L. Castelino ${ }^{1,2^{*}}$ (D) Timothy Saunder ${ }^{3}$, Alex Kitsos ${ }^{4}$, Gregory M. Peterson ${ }^{4}$, Matthew Jose ${ }^{5,6}$, Barbara Wimmer ${ }^{7}$,
} Masuma Khanam ${ }^{8}$, Woldesellassie Bezabhe ${ }^{9}$, Jim Stankovich ${ }^{10}$ and Jan Radford ${ }^{11}$

\begin{abstract}
Background: Chronic kidney disease (CKD) affects drug elimination and patients with CKD require appropriate adjustment of renally cleared medications to ensure safe and effective pharmacotherapy. The main objective of this study was to determine the extent of potentially inappropriate prescribing (PIP; defined as the use of a contraindicated medication or inappropriately high dose according to the kidney function) of renally-cleared medications commonly prescribed in Australian primary care, based on two measures of kidney function. A secondary aim was to assess agreement between the two measures.

Methods: Retrospective analysis of routinely collected de-identified Australian general practice patient data (NPS MedicineWise Medicinelnsight from January 1, 2013, to June 1, 2016; collected from 329 general practices). All adults (aged $\geq 18$ years) with CKD presenting to general practices across Australia were included in the analysis. Patients were considered to have CKD if they had two or more estimated glomerular filtration rate (eGFR) recorded values $<60 \mathrm{~mL} / \mathrm{min} / 1.73 \mathrm{~m}^{2}$, and/or two urinary albumin/creatinine ratios $\geq 3.5 \mathrm{mg} / \mathrm{mmol}$ in females $(\geq 2.5 \mathrm{mg} / \mathrm{mmol}$ in males) at least 90 days apart. PIP was assessed for 49 commonly prescribed medications using the CockcroftGault (CG) equation/eGFR as per the instructions in the Australian Medicines Handbook.
\end{abstract}

Results: A total of 48,731 patients met the Kidney Health Australia (KHA) definition for CKD and had prescriptions recorded within 90 days of measuring serum creatinine (SCr)/estimated glomerular filtration rate (eGFR). Overall, 28, 729 patients were prescribed one or more of the 49 medications of interest. Approximately 35\% $(n=9926)$ of these patients had at least one PIP based on either the Cockcroft-Gault (CG) equation or eGFR (CKD-EPI; CKDEpidemiology Collaboration Equation). There was good agreement between CG and eGFR while determining the appropriateness of medications, with approximately $97 \%$ of the medications classified as appropriate by eGFR also being considered appropriate by the CG equation.

Conclusion: This study highlights that PIP commonly occurs in primary care patients with CKD and the need for further research to understand why and how this can be minimised. The findings also show that the eGFR provides clinicians a potential alternative to the CG formula when estimating kidney function to guide drug appropriateness and dosing.

Keywords: Inappropriate prescribing, Drug dosing, Kidney disease

\footnotetext{
* Correspondence: Ronald.Castelino@sydney.edu.au

${ }^{1}$ Pharmacology and Clinical Pharmacy, University of Sydney, Sydney School

of Nursing, Camperdown, Sydney 2000, Australia

Blacktown Hospital, Blacktown, New South Wales, Australia

Full list of author information is available at the end of the article
}

C C The Author(s). 2020 Open Access This article is licensed under a Creative Commons Attribution 4.0 International License, which permits use, sharing, adaptation, distribution and reproduction in any medium or format, as long as you give appropriate credit to the original author(s) and the source, provide a link to the Creative Commons licence, and indicate if changes were made. The images or other third party material in this article are included in the article's Creative Commons licence, unless indicated otherwise in a credit line to the material. If material is not included in the article's Creative Commons licence and your intended use is not permitted by statutory regulation or exceeds the permitted use, you will need to obtain permission directly from the copyright holder. To view a copy of this licence, visit http://creativecommons.org/licenses/by/4.0/ The Creative Commons Public Domain Dedication waiver (http://creativecommons.org/publicdomain/zero/1.0/) applies to the data made available in this article, unless otherwise stated in a credit line to the data. 


\section{Background}

The prevalence of chronic kidney disease (CKD) is rapidly increasing worldwide, alongside its complications [1-3]. Most people with CKD are prescribed a multitude of drugs to treat the underlying cause of kidney disease, or its numerous complications and comorbidities [2, 3]. The reduction in kidney function requires adaptation of treatment regimens as the pharmacokinetics and pharmacodynamics of many drugs are altered. Dosing errors are common in CKD and can cause adverse effects and poor outcomes [2].

Previous studies have reported potentially inappropriate prescribing (PIP) of medications in CKD (defined as the use of a contraindicated medication or inappropriately high dose according to the kidney function) ranging from 13 to $80 \%$, with most of the medications being initiated in the community setting $[2,4]$. In Australia, the prevalence of PIP in patients with renal impairment in primary care has received less attention. One study reported that $32 \%$ of patients with CKD were receiving PIP at the time of admission to hospital [2].

The automated reporting of estimated glomerular filtration rate (eGFR) calculated from the modification of diet in renal disease (MDRD) or CKD epidemiology collaboration equation (CKD-EPI) is now routinely provided by laboratories whenever a serum creatinine $(\mathrm{SCr})$ value is measured, as a tool to enhance the identification and classification of CKD [5]. Most of the drug dosing studies to date, however, have used the Cockcroft-Gault (CG) equation to estimate kidney function as creatinine clearance $(\mathrm{CrCl})$, which includes a weight component [6]. While the CG equation is still the preferred equation for drug dosage adjustment by most drug information sources, it is cumbersome to calculate in the busy context of a general practice consultation.

Given this background, the main objective of this study was to determine the extent of PIP of renallycleared medications commonly prescribed in Australian primary care, based on two separate estimates of kidney function (CG and CKD-EPI).

\section{Methods}

This retrospective study included data collected by MedicineInsight, developed and managed by NPS MedicineWise. MedicineInsight is a large-scale national data program in Australia to extract and collate longitudinal, whole-of-practice data from the clinical information systems of consenting general practices. De-identified patient data collected include demographics, encounters (not including progress notes), diagnoses, prescriptions and pathology tests. As of July 2017, MedicineInsight had recruited 650 general practices with data pertaining to 3.6 million patients $[3,7,8]$. The Institutional Human Research Ethics Committee approved the study
(H0015651). The study is reported as per the reporting of studies conducted using observational routinely collected health data statement for pharmacoepidemiology (RECORD-PE) guideline [9].

We used MedicineInsight data from January 1, 2013 to June 1, 2016, collected from 329 general practices distributed across Australia. Patients were initially included if at the time of data extract they were aged at least 18 years, met the Royal Australian College of General Practice (RACGP) definition of an "active" patient (attended at least three times at the same general practice within a two-year period), and could be diagnosed with CKD based on their laboratory pathology results (having two or more eGFR values less than $60 \mathrm{~mL} / \mathrm{min} / 1.73 \mathrm{~m}^{2}$, and/ or two urinary albumin/creatinine ratios $(\mathrm{ACR}) \geq 3.5$ $\mathrm{mg} / \mathrm{mmol}$ in females or $\geq 2.5 \mathrm{mg} / \mathrm{mmol}$ in males, at least 90 days apart) [1].

A total of 60,433 patients out of 1.48 million (approximately $4 \%$ ) in the dataset met the Kidney Health Australia (KHA) guidelines for the diagnosis of CKD [1]. For assessing the quality use of medicines (QUM) in kidney disease we included a total of 49 medications, which were part of a national campaign to improve prescribing in the elderly in 2012 [10]. The list was adapted to include some medications that were commonly associated with PIP in other research [2]. Patients' medications were included if they were prescribed within 90 days following the pathology test. PIP was defined as prescribing of a medication that is contraindicated or at an inappropriately high dose according to the patient's kidney function. Appropriateness was assessed using the Australian Medicines Handbook (AMH) [11]. Only medications that had clear recommendations were included in the analysis. Medications with ambiguous dosage adjustment recommendations were excluded from the analysis e.g. Ramipril- "In patients with renal impairment, elderly or taking a diuretic, initially 2.5mg once daily" [11]. Additionally, medications that were available in combination were assessed for PIP separately. For example; metformin and sitagliptin were assessed for PIP and reported separately. Examples of drugs and recommendations extracted from the $\mathrm{AMH}$ are presented in Additional file 1. The complete list of medications and recommendations is available on request.

\section{Statistical analysis}

Descriptive statistics were used to describe the data, with mean \pm standard deviation (SD) and percentages/proportions. PIP of medications, i.e. both potentially contraindicated and inappropriately dosed medications, were compared for appropriateness between the CKD-EPI and CG equations (patients with weight and height documented). The level of agreement in evaluating appropriateness between the equations was calculated by 
Cohen's kappa and Gwet first-order agreement coefficient (AC1) [12]. For Cohen's Kappa, a value of $<0.6$ was defined as poor agreement, $0.6-0.8$ as moderate agreement, 0.8 to $<0.9$ as good agreement and $\geq 0.9$ as excellent agreement. Gwet AC1 provides an alternative in circumstances where Kappa is low despite a high level of agreement and has been shown to provide a more stable inter-rater reliability coefficient than Cohen's kappa [12]. All data cleaning and manipulation, and statistical analyses were completed using the statistical and graphical computing language of $\mathrm{R}$ [13]. A $p$ value of $<$ 0.05 was considered statistically significant.

\section{Results}

A total of 48,731 patients met the KHA definition for CKD and had prescriptions recorded within 90 days of measuring kidney function. Overall, 28,729 patients were prescribed one or more of the 49 medications of interest (Table 1). Over $90 \%$ of these patients $(n=25,975)$ were $\geq$ 65 years of age and $55.7 \%(n=15,993)$ were female. The mean (SD) number of medications and medical conditions were 8.4 (3.8) and 2.2 (1.0), respectively. Over $80 \%$ $(n=23,998)$ of the patients had hypertension, while over $40 \%$ had diabetes and/cardiovascular disease $(n=13,292$ and 13,611, respectively). Among the 28,729 patients, almost all 98.5\% $(n=28,315)$ were in Stage 3, 4 and 5 CKD. The most common drug class prescribed across the study sample were agents pertaining to the reninangiotensin system (RAS).

\section{Potentially inappropriate prescribing}

A breakdown of PIP across the different stages of CKD is provided in Fig. 1. Overall, 35\% $(n=9926)$ patients had at least one PIP based on either $\mathrm{CG} \mathrm{CrCl}$ or eGFR. Approximately $6.5 \%(n=1866)$ and $1.8 \%(n=505)$ were prescribed 2 and 3 or more potentially inappropriate medications (PIMs), respectively (Table 2). A total of 1171 patients $(4.1 \%)$ were prescribed both a contraindicated medication and a medication at an inappropriate dose as per their kidney function.

Analgesics, prescribed across $7.2 \%$ patients $(n=2082)$, were the most frequent inappropriate class of medication [ $n=1536$ ( $73.8 \%$ of patients prescribed the drugs)] followed by medications for diabetes [prescribed $n=$ 8730 (30.4\%); PIP $n=3384$ (44.1\%)] and beta-blockers [prescribed $n=4832$ (16.8\%); PIP $n=1849(38.2 \%)]$. Vildagliptin [prescribed $n=355$ (1.2\%); PIP $n=274$ (77.2\%)] followed by fenofibrate [prescribed $n=1939$ (6.7\%); PIP $n=1346(69.4 \%)]$ were the most commonly prescribed medications at an inappropriate dose, whilst dapagliflozin [prescribed $n=296$ (1\%); PIP $n=245 \quad(82.8 \%)]$ followed by alendronate [prescribed $n=791(2.8 \%)$; PIP $n=251(31.7 \%)]$ had the highest rates of use when contraindicated either by $\mathrm{CG} \mathrm{CrCl}$ or eGFR (Table 3).
Table 1 Characteristics of the study sample $(n=28,729)$

\begin{tabular}{|c|c|}
\hline Demographics & Number (\%) \\
\hline \multicolumn{2}{|l|}{ Age (years) } \\
\hline $20-29$ & $6(0.02)$ \\
\hline $30-39$ & $61(0.21)$ \\
\hline $40-49$ & $257(0.89)$ \\
\hline $50-59$ & $1039(3.62)$ \\
\hline $60-69$ & $4234(14.74)$ \\
\hline $70-79$ & $10,219(35.57)$ \\
\hline $80-89$ & $10,434(36.32)$ \\
\hline $90+$ & $2479(8.63)$ \\
\hline Male Gender & $12,736(44.3)$ \\
\hline \multicolumn{2}{|l|}{ CKD Risk Factors } \\
\hline Hypertension & $23,998(83.2)$ \\
\hline CVD & $13,611(47.4)$ \\
\hline Diabetes & $13,292(46.3)$ \\
\hline Number of medications [Mean (SD)] & $8.42(3.75)$ \\
\hline \multicolumn{2}{|c|}{ Top 5 medications categorised according to the ATC groups } \\
\hline Agents acting on the renin-angiotensin system & $20,391(71.0)$ \\
\hline Analgesics & $16,084(56.0)$ \\
\hline Drugs for acid-related disorders & $15,861(55.2)$ \\
\hline Antithrombotic drugs & $11,691(40.7)$ \\
\hline Diuretics & $10,965(38.2)$ \\
\hline \multicolumn{2}{|l|}{ Stages of CKD } \\
\hline Stage $1 \geq 90 \mathrm{~mL} / \mathrm{min} / 1.73 \mathrm{~m}^{2}$ & $27(0.1)$ \\
\hline Stage $260-89 \mathrm{~mL} / \mathrm{min} / 1.73 \mathrm{~m}^{2}$ & $387(6.8)$ \\
\hline Stage $3 a$ $45-59 \mathrm{~mL} / \mathrm{min} / 1.73 \mathrm{~m}^{2}$ & $18,553(64.6)$ \\
\hline Stage $3 b$ 30-44 mL/min/1.73m² & $7539(26.2)$ \\
\hline Stage $415-29 \mathrm{~mL} / \mathrm{min} / 1.73 \mathrm{~m}^{2}$ & $1955(6.8)$ \\
\hline Stage $5<15 \mathrm{~mL} / \mathrm{min} / 1.73 \mathrm{~m}^{2}$ & $268(0.9)$ \\
\hline
\end{tabular}

CVD Cardiovascular disease, ATC Anatomical Therapeutic Chemical classification system

Codeine, glibenclamide and glimepiride were associated with PIP in all patients prescribed these drugs, as the AMH recommends their avoidance in renal impairment, and these were excluded from the final analysis.

\section{Agreement between eGFR (CKD-EPI) and $\mathrm{CrCl}$ (CG equation)}

Overall, there was good agreement between $\mathrm{CG} \mathrm{CrCl}$ and eGFR (CKD-EPI) when determining the appropriateness of medications. Approximately $97 \%$ of medications that were classified as appropriate by eGFR were considered to be appropriate by the CG equation, while 88.1 and $61.1 \%$ of the medications considered to be contraindicated and inappropriately dosed by eGFR, were considered to be contraindicated and inappropriately dosed by the CG equation, respectively (Fig. 2). The top 

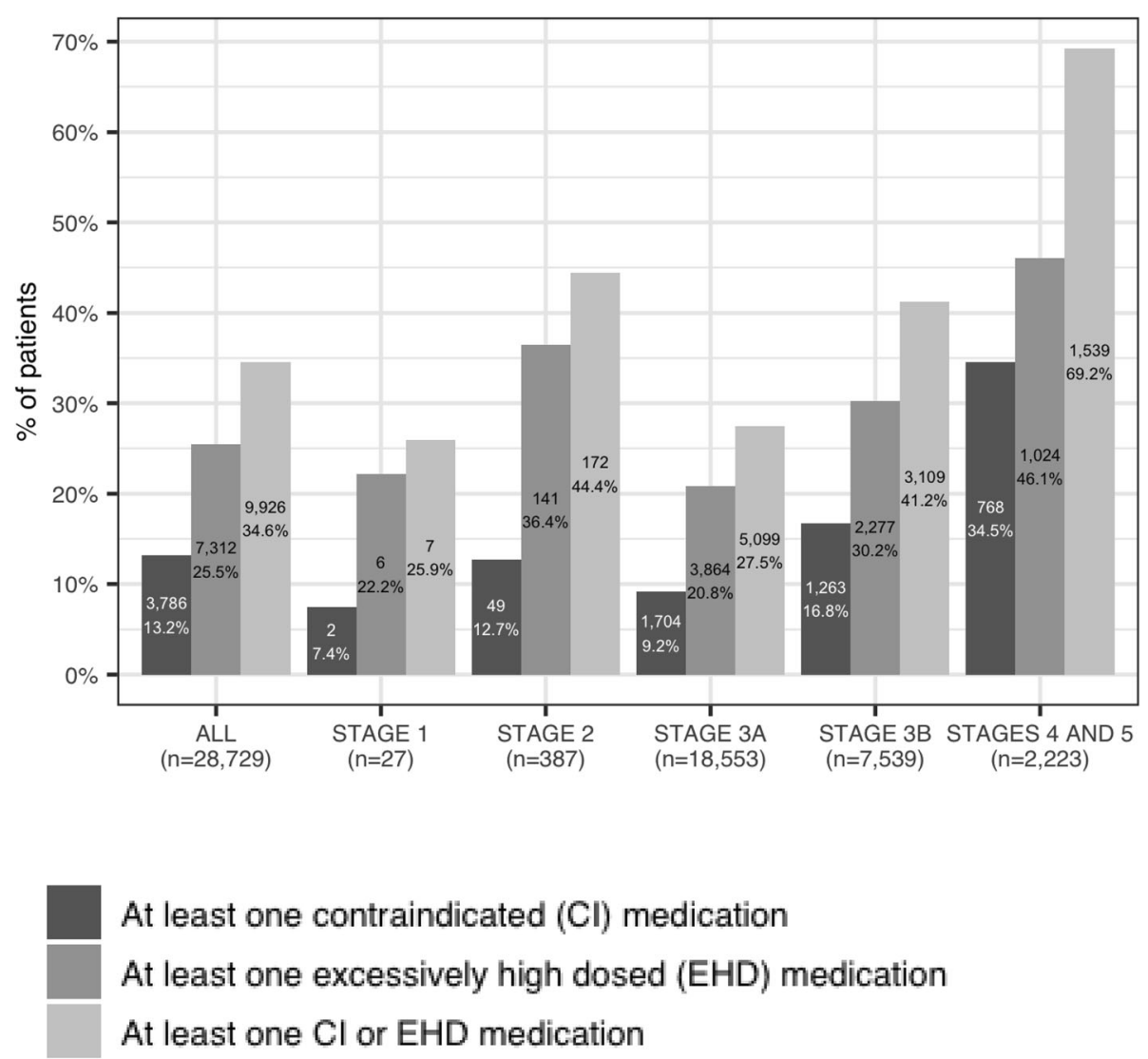

Fig. 1 Potential inappropriate prescribing as per CKD stage

Table 2 Potentially inappropriate medications (PIMs) in the study sample

\begin{tabular}{ll}
\hline Characteristic & Number (\%) \\
\hline PIMs & $18,803(65.4)$ \\
0 & $7555(26.3)$ \\
1 & $1866(6.5)$ \\
2 & $505(1.8)$ \\
$\geq 3$ & $7312(25.5)$ \\
Patients with potentially inappropriate dose & 21,417 (74.5) \\
0 & $5983(20.8)$ \\
1 & $1143(4.0)$ \\
2 & $186(0.6)$ \\
$\geq 3$ & $3786(13.2)$ \\
Patients with potentially contraindicated medication & $24,943(86.8)$ \\
0 & $3494(12.2)$ \\
1 & $265(0.9)$ \\
2 & $27(0.1)$ \\
Patients with both potentially inappropriate dose and contraindicated medication & $1171(4.1)$ \\
\hline
\end{tabular}


Table 3 Medications with potentially inappropriate prescribing

\begin{tabular}{|c|c|c|c|c|c|}
\hline $\begin{array}{l}\text { Medications with } \\
\text { potentially inappropriate } \\
\text { dose }\end{array}$ & $\begin{array}{l}\text { Patients } \\
\text { prescribed N } \\
(\%)\end{array}$ & $\begin{array}{l}\text { Patients with } \\
\text { inappropriately high } \\
\text { dose drug } \\
\mathrm{N}(\%)\end{array}$ & $\begin{array}{l}\text { Medications potentially } \\
\text { contraindicated }\end{array}$ & $\begin{array}{l}\text { Patients } \\
\text { prescribed N } \\
(\%)\end{array}$ & $\begin{array}{l}\text { Patients with potentially } \\
\text { contraindicated medication N } \\
\text { (\%) }\end{array}$ \\
\hline \multicolumn{3}{|l|}{ Antidiabetic Medications } & \multicolumn{3}{|l|}{ Antidiabetic Medications } \\
\hline Vildagliptin & $355(1.2)$ & $274(77.2)$ & Dapagliflozin & $296(1.0)$ & $245(82.8)$ \\
\hline Saxagliptin & $205(0.7)$ & $117(57.1)$ & Acarbose & $81(0.3)$ & $12(14.8)$ \\
\hline Sitagliptin & $1534(5.3)$ & $742(48.4)$ & Exenatide & $313(1.1)$ & $18(5.8)$ \\
\hline Metformin & $8046(28.0)$ & 2885 (35.9) & Metformin & $8046(28.0)$ & $37(0.5)$ \\
\hline Alogliptin & $17(0.1)$ & $5(29.4)$ & \multicolumn{3}{|c|}{ Anticoagulant Medications } \\
\hline \multicolumn{3}{|c|}{ Lipid Lowering Medications } & Rivaroxaban & $1230(4.3)$ & $99(8.0)$ \\
\hline Fenofibrate & $1939(6.7)$ & $1346(69.4)$ & Dabigatran & $492(1.7)$ & $34(6.9)$ \\
\hline Rosuvastatin & $8529(29.7)$ & $525(6.2)$ & Apixaban & $938(3.3)$ & $40(4.3)$ \\
\hline \multicolumn{3}{|c|}{ Antihypertensive Medications } & \multicolumn{3}{|c|}{ Cardiovascular Medications } \\
\hline Atenolol & $4832(16.8)$ & $1849(38.3)$ & Moxonidine & $1675(5.8)$ & $447(26.7)$ \\
\hline Moxonidine & $1675(5.8)$ & $43(2.6)$ & Spironolactone & 3050 (10.6) & $665(21.8)$ \\
\hline \multicolumn{3}{|l|}{ Antiarrhythmics } & \multicolumn{3}{|l|}{ Bisphosphonates } \\
\hline Digoxin & $2567(8.9)$ & $24(0.9)$ & Alendronate & $791(2.8)$ & $251(31.7)$ \\
\hline \multicolumn{3}{|c|}{ Anticoagulant Medications } & Risedronate & $619(2.2)$ & $118(19.1)$ \\
\hline Rivaroxaban & $1230(4.3)$ & $237(19.3)$ & Others & & \\
\hline Dabigatran & $492(1.7)$ & $39(7.9)$ & Teriparatide & $7(0.0)$ & $2(28.6)$ \\
\hline \multicolumn{3}{|l|}{ Bisphosphonates } & Strontium & $205(0.7)$ & $43(21.0)$ \\
\hline Clodronate & $10(0.03)$ & $5(50)$ & Dextropropoxyphene & $105(0.4)$ & $33(31.4)$ \\
\hline Zoledronate & $24(0.1)$ & $1(4.2)$ & Pramipexole & $523(1.8)$ & $100(19.1)$ \\
\hline \multicolumn{3}{|l|}{ Antihistamines } & Probenecid & $115(0.4)$ & $1(0.9)$ \\
\hline Nizatidine & $283(1.0)$ & $170(60.1)$ & & & \\
\hline Cimetidine & $15(0.1)$ & $3(20.0)$ & & & \\
\hline Cetirizine & $261(0.9)$ & $50(19.2)$ & & & \\
\hline \multicolumn{6}{|l|}{ Psychotropic Medications } \\
\hline Paliperidone & $6(0.02)$ & $4(66.7)$ & & & \\
\hline Desvenlafaxine & $572(2.0)$ & $70(12.2)$ & & & \\
\hline Duloxetine & $846(2.9)$ & $87(10.3)$ & & & \\
\hline Venlafaxine & $1050(3.7)$ & $47(4.5)$ & & & \\
\hline Varenicline & $150(0.5)$ & $6(4.0)$ & & & \\
\hline \multicolumn{6}{|l|}{ Neurological Medications } \\
\hline Tramadol & $571(2)$ & 67 (11.7) & & & \\
\hline Gabapentin & $341(1.2)$ & $30(8.8)$ & & & \\
\hline Levetiracetam & $179(0.6)$ & $9(5)$ & & & \\
\hline Pregabalin & $4642(16.2)$ & $190(4.1)$ & & & \\
\hline Pramipexole & $523(1.8)$ & $3(0.6)$ & & & \\
\hline \multicolumn{6}{|l|}{ Others } \\
\hline Tolterodine & $20(0.1)$ & $2(10.0)$ & & & \\
\hline Solifenacin & 458 (1.6) & $21(4.6)$ & & & \\
\hline
\end{tabular}

Codeine, Glibenclamide and Glimepiride were prescribed inappropriately in all patients and is not presented in the table; Combination medications were assessed for PIP separately 


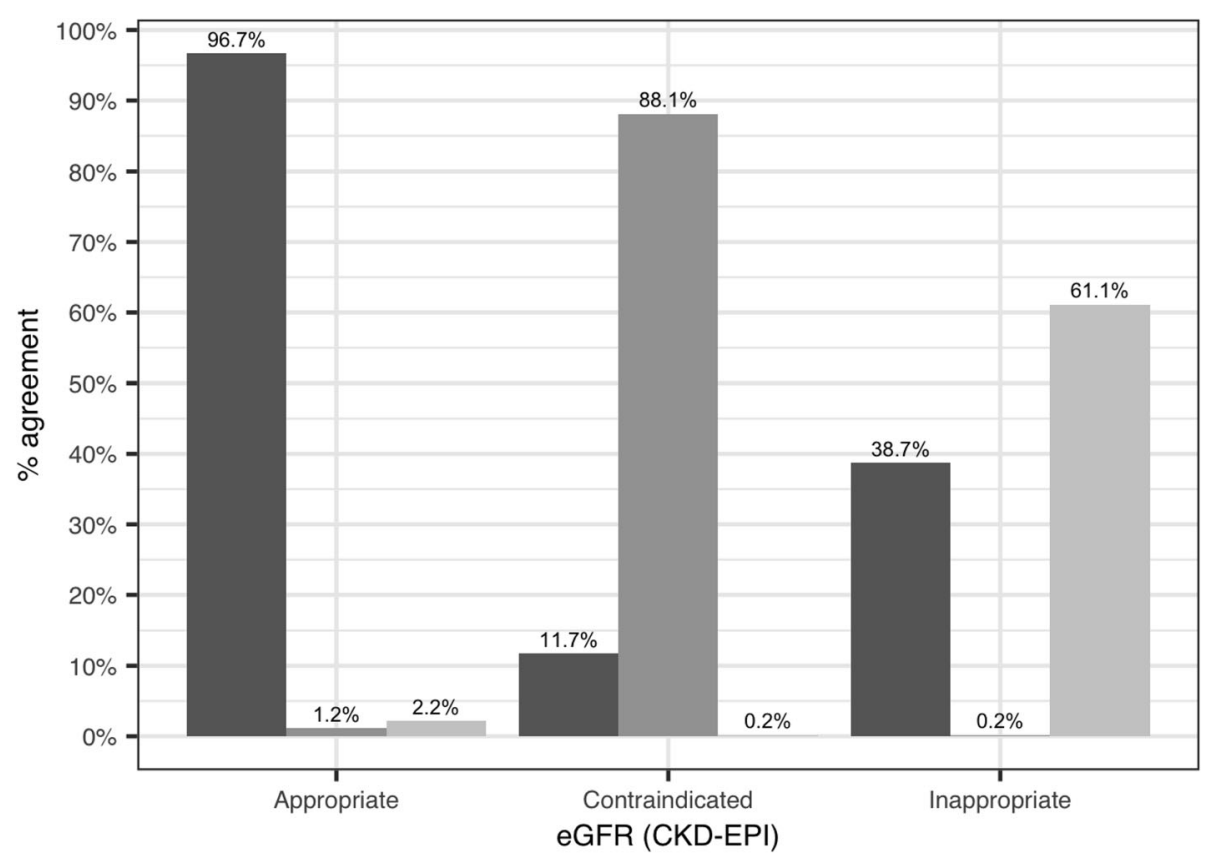

\section{Cockroft-Gault}

Appropriate

\section{Contraindicated}

Inappropriate

Fig. 2 Agreement of equations in determining PIP

3 medications in disagreement between the two equations are presented in Table 4. A total of 40 medications from the 49 of interest, that had been rated PIP at least once, were tested for inter-rater agreement. Twentyseven medications scored a Cohen's kappa value $<0.6$ whereas Gwet's AC1 scores were between 0.75-1.0.

\section{Discussion}

The results demonstrate that Australian general practice patients with CKD are frequently prescribed PIP. Approximately $35 \%$ of the patients were prescribed at least one PIP. The findings have corroborated the high rate of potentially contraindicated medications and inappropriate dosing found in international studies, including a systematic review that reported rates of PIP between 13 to $80 \%[2,4]$. These results highlight the need for further research to determine the reasons, leading to interventions to optimise prescribing in patients with CKD in general practice.

The extent of PIP in our study and the previous literature highlights the complexity of prescribing in CKD and could be due to the contribution of several factors. Firstly, in Australia there is a lack of up-to-date accessible guidelines on drug dose adjustments in patients with impaired kidney function. Another important aspect to consider is the inconsistencies with dosage adjustment recommendations between different drug information sources, as well as the product information of different brands of the same drug $[14,15]$. It is important to note that most drug information sources provide dosage adjustment based on the CG equation rather than eGFR formulae (MDRD/CKD-EPI), whilst eGFR (especially CKD-EPI) based formulae have been found to be the most accurate indicator of kidney function [16]. Secondly, many of the recommendations based on the CG equation are questionable due to the variability in creatinine assays at the time and were prior to $\mathrm{SCr}$ being isotope dilution mass spectrometry (IDMS) standardised. CG-estimated GFR results are 5-10\% higher using the standardised $\mathrm{SCr}$ measurements compared to the nonstandardised $\mathrm{SCr}$ and relying on the CG equation could lead to unintended consequences, including insufficient 
Table 4 Top 3 medications considered in disagreement between $\mathrm{CG} \mathrm{CrCl}$ and eGFR (CKD-EPI)

\begin{tabular}{|c|c|c|c|}
\hline CKD-EPI eGFR & CG Equation & Medication & $N(\%)$ \\
\hline \multirow[t]{6}{*}{ Appropriate } & \multirow[t]{3}{*}{ Contraindicated } & Spironolactone & $229(27.8)$ \\
\hline & & Alendronate & $186(22.5)$ \\
\hline & & Risedronate & $105(12.7)$ \\
\hline & \multirow[t]{3}{*}{ Inappropriate dose } & Atenolol & $501(32.3)$ \\
\hline & & Metformin & $272(17.5)$ \\
\hline & & Sitagliptin & $169(10.9)$ \\
\hline \multirow[t]{6}{*}{ Contraindicated } & \multirow[t]{3}{*}{ Appropriate } & Moxonidine & $270(30.5)$ \\
\hline & & Spironolactone & $241(27.3)$ \\
\hline & & Dapagliflozin & $177(20)$ \\
\hline & \multirow[t]{3}{*}{ Inappropriate dose } & Moxonidine & $7(46.7)$ \\
\hline & & Metformin & $4(26.7)$ \\
\hline & & Rivaroxaban & $4(26.7)$ \\
\hline \multirow[t]{5}{*}{ Inappropriate dose } & \multirow[t]{3}{*}{ Appropriate } & Metformin & $1812(35.5)$ \\
\hline & & Fenofibrate & 915 (17.9) \\
\hline & & Atenolol & $675(13.2)$ \\
\hline & \multirow[t]{2}{*}{ Contraindicated } & Rivaroxaban & $13(52.0)$ \\
\hline & & Metformin & $12(48.0)$ \\
\hline
\end{tabular}

dose adjustments for kidney function $[17,18]$. However, the clinical significance of this theoretical issue is unknown and needs to be evaluated further. Hence, current recommendations include using either $C G$ equation due to considerable experience with the formula even if it is based on creatinine assays not in use. It is also appropriate to use eGFR formula (CKD-EPI) for most drugs without body surface area (BSA) adjustment $[1,16]$.

The nature of the electronic health record (eHR) may also be a potential factor for PIP. The current eHR may not alert prescribers to appropriately adjust dosages of medications cleared by the kidney unless the patient has CKD recorded as a diagnosis. Only $20 \%$ of the patients included had a formal diagnosis of CKD documented whilst all patients had laboratory evidence of CKD and this lack of coding of CKD as a condition may have had a role in the PIP findings $[7,8]$. Whilst the overall prevalence of CKD in our study was comparable to the previous Australian Bureau of Statistics (ABS) results, the prevalence is lower than previous International literature. The potential reasons for the lower prevalence have been described in detail elsewhere [3]. It is important to note that in many older people with stable eGFR values from 45 to $59 \mathrm{~mL} / \mathrm{min} / 1.73 \mathrm{~m}^{2}$ debate on the definition and staging of CKD exists as to whether CKD may be over diagnosed. However, these values are a sign of impaired kidney function that could affect the clearance of drugs. Hence, it is essential to consider renal function when prescribing renally-cleared medications as the PIP may lead to adverse outcomes.
The agreement between the two equations (CG and CKD-EPI) was excellent, with $97 \%$ of the medications rated as appropriate by eGFR being also rated as appropriate by the $C G$ equation. Previous studies comparing drug doses derived from eGFR equations and CG have commonly reported discordance rates between 10 and $40 \%[19,20]$. These results highlight that for most patients with renal impairment the same recommendation between eGFR or CG estimate can be used, with any difference in the kidney function estimate unlikely to lead to an overdose [21] However, it is important for some drugs, and the potential clinical significance of disagreement between eGFR and CG-based dosing regimens should be minimised by using sound clinical judgment [22]. For example, our study showed that rivaroxaban was one of the medications associated with disagreement between the equations. A recent study by Szummer et al. comparing eGFR (CKD-EPI, MDRD) and the CG equation suggested that when prescribing one of the novel oral anticoagulants, the CG equation should be considered, as it provides a more conservative approach for avoiding drug exposure and reducing the risk of bleeding [23]. A similar approach is recommended by the National Kidney Disease Education Program (NKDEP) in the USA and by KHA, where eGFR can be used for dosage adjustment for most drugs (without BSA adjustment) except for drugs with a narrow therapeutic index (e.g. anticoagulants), where conservative kidney function estimates and corresponding doses are recommended, particularly if therapeutic drug monitoring is not readily available [16].

Most of the medications with PIP were consistent with previous studies [2]. Antidiabetic agents and cardiovascular drugs were commonly associated with PIP, which is not surprising given that both diabetes and CVD often co-exist with CKD. Almost half of our patients were being treated for diabetes and CVD. A large proportion of oral antidiabetic agents are excreted by the kidney [11]. It is likely that concomitant chronic diseases complicate and confound the treatment of each other. These medications are adjusted frequently in response to cardiac, renal or electrolyte disturbances, and are at a higher risk of being potentially inappropriate.

It is important to note that for some medications commonly prescribed in the study (for example, atenolol) clinical markers, such as heart rate and blood pressure, are often more important than kidney function in guiding dosage adjustment. Additionally, some medications do not have adequate published data in patients with renal impairment and may have been conservatively recommended as to be avoided rather than having an increased potential for toxic effects [11].

Our study also showed that PIP was common across all stages of CKD. Although stages 1, 2 and 3a CKD 
seldom impact on the prescribing of renally cleared medications, several common medications such as metformin, gliptins and SGLT2 inhibitors do have specific recommendations in patients with early stages of CKD. Previous studies in patients with advanced CKD have shown contrasting results. Some studies have reported that in patients with advanced CKD the likelihood of PIP is less due to more vigilant monitoring and nephrology consultations, while other studies have shown an increased number of problems [24-26]. Further research to understand the phenomenon of PIP in general practice is needed, possibly leading to the design of interventions to optimise medication prescribing in patients with CKD. Optimal use of current eHR systems to flag renally-impaired patients so that PIP is identified is likely to be part of an intervention.

The major strength of the current study is that it assessed prescriptions in primary care in a large cohort of patients. Previous Australian studies of inappropriate drug prescriptions in CKD have focussed on older people in the community and aged care settings, or when patients were admitted to the hospital [4]. However, the study does have some limitations. Prescribers may not always have had pathology results available at the time of prescribing. However, we evaluated the extent of PIP for medications prescribed within 90 days of the availability of a kidney function assessment. We did not examine any adverse clinical outcomes associated with PIP. Additionally, prescribing may be appropriate at times with benefits outweighing the additional risks or if no safer alternatives are available.

\section{Conclusion}

Our study highlights that PIP is common in Australian general practice, underlining the complexity of prescribing for patients with CKD. Understanding situations where prescribing is truly inappropriate would assist in the design of interventions to improve safe medication prescribing in patients with CKD. Our study also shows that although $\mathrm{CrCl}$ using the CG formula has been the most common method of estimating kidney function for drug dosing purposes for over 40 years, the widespread availability and extensive clinical use of eGFR now provides clinicians with a potential alternative. However, careful consideration of the risk-benefit ratio of individual drugs and doses within each patient is warranted.

\section{Supplementary information}

Supplementary information accompanies this paper at https://doi.org/10. 1186/s12882-020-01862-1.

Additional file 1. Examples of renally cleared medications and dosage recommendations from the $\mathrm{AMH}$.

\section{Additional file 2.}

\section{Abbreviations}

AC1: Agreement coefficient; ACR: Albumin/creatinine ratio; AMH: Australian Medicines Handbook; BSA: Body surface area; CVD: Cardiovascular disease; CKD: Chronic kidney disease; CKD-EPI: CKD-Epidemiology Collaboration Eq:i CG: Cockcroft-Gault; CrCl: Creatinine clearance; eHR: electronic health record; eGFR: estimated glomerular filtration rate; IDMS: Isotope dilution mass spectrometry; KHA: Kidney Health Australia; MDRD: Modification of diet in renal disease; NKDEP: National Kidney Disease Education Program; PIP: Potentially inappropriate prescribing; QUM: Quality use of medicines; RACGP: Royal Australian College of General Practice; SCr: Serum creatinine; SGLT2: Sodium glucose cotransport inhibitors

\section{Acknowledgements}

The authors would like to thank Medicinelnsight, NPS for providing us with the data for this project.

\section{Declarations}

Ethics approval and consent to participate (provide full name of ethics committee). The University of Tasmania Human Research Ethics Committee approved the study (H0015651). As this was a retrospective study no consent was required from the participants.

\section{Authors' contributions}

Conception and study design: R.L.C; data acquisition: R.L.C., JR, GP.; data analysis R.L.C., TS, AK, JS; Data critique and interpretation: RLC, TS, AK, GMP, $M J, B W, M K, W B, J S$, and JR; manuscript preparation: RLC; Manuscript critique: RLC, TS, AK, GMP, MJ,BW, MK, WB, JS, and JR. All authors have read, agreed, attest to the accuracy of the results and approved the final version of the manuscript.

\section{Funding}

This study did not receive any funding.

\section{Availability of data and materials}

Yes, if required after appropriate grant of permission from Medicinelnsight.

Consent for publication

All authors listed have consented to the publication.

\section{Competing interests}

Jan Radford serves on the data governance board of NPS MedicineWise. None of the other authors have any competing interest.

\section{Author details}

${ }^{1}$ Pharmacology and Clinical Pharmacy, University of Sydney, Sydney School of Nursing, Camperdown, Sydney 2000, Australia. ²Blacktown Hospital, Blacktown, New South Wales, Australia. ${ }^{3}$ School of Medicine, University of Tasmania, Private Bag 34, Hobart, TAS 7001, Australia. ${ }^{4}$ Faculty of Health Science, University of Tasmania, Churchill Avenue, Sandy Bay, TAS 7001, Australia. ${ }^{5}$ Faculty of Medicine, University of Tasmania, Private Bag 96, Hobart, TAS 7001, Australia. ${ }^{6}$ Division of Medicine, Royal Hobart Hospital, Private Bag 96, Hobart, TAS 7001, Australia. ${ }^{7}$ School of Medicine, University of Tasmania, Private Bag 26, Hobart, TAS 7001, Australia. ${ }^{8}$ School of Health Sciences, University of Tasmania, Churchill Avenue, Sandy Bay, TAS 7005, Australia. ${ }^{9}$ School of Medicine, University of Tas, Private Bag 26, Hobart, TAS 7001, Australia. ${ }^{10}$ Department of Neuroscience, Monash University, 99 Commercial Rd, Melbourne, VIC 3004, Australia. "11Launceston Clinical School, School of Medicine, Locked Bag 1377, Launceston, Tas 7250, Australia.

Received: 16 September 2019 Accepted: 21 May 2020

Published online: 05 June 2020

\section{References}

1. Chronic Kidney Disease (CKD) Management in General Practice. 2nd ed. Melbourne: Kidney Health Australia; 2012. https://kidney.org.au/cms_ uploads/docs/chronic-kidney-disease-management-in-primary-care-4thedition-handbook.pdf. 
2. Doody HK, Peterson GM, Watson D, Castelino RL. Retrospective evaluation of potentially inappropriate prescribing in hospitalized patients with renal impairment. Curr Med Res Opin. 2015;31(3):525-35.

3. Radford J, Kitsos A, Stankovich J, Castelino R, Khanam M, Jose M, Peterson G, Saunder T, Wimmer B, Razizaidi T. Epidemiology of chronic kidney disease in Australian general practice: National Prescribing Service MedicineWise Medicinelnsight dataset. Nephrology. 2018;23:23.

4. Tesfaye WH, Castelino RL, Wimmer BC, Zaidi STR. Inappropriate prescribing in chronic kidney disease: A systematic review of prevalence, associated clinical outcomes and impact of interventions. Int J Clin Pract. 2017;71(7): e12960.

5. Johnson DW, Jones GR, Mathew TH, Ludlow MJ, Doogue MP, Jose MD, Langham RG, Lawton PD, McTaggart SJ, Peake MJ, et al. Chronic kidney disease and automatic reporting of estimated glomerular filtration rate: new developments and revised recommendations. Med J Aust. 2012;197(4):224-5.

6. Cockcroft DW, Gault MH. Prediction of creatinine clearance from serum creatinine. Nephron. 1976;16(1):31-41.

7. Khanam MA, Kitsos A, Stankovich J, Castelino R, Jose M, Peterson GM, Wimmer B, Razi Zaidi T, Radford J. Association of continuity of care with blood pressure control in patients with chronic kidney disease and hypertension. Aust J Gen Pract. 2019;48(5):300-6.

8. Kitsos A, Peterson GM, Jose MD, Khanam MA, Castelino RL, Radford JC. Variation in documenting diagnosable chronic kidney disease in general medical practice: implications for quality improvement and research. J Prim Care Community Health. 2019;10:2150132719833298.

9. Langan SM, Schmidt SA, Wing K, Ehrenstein V, Nicholls SG, Filion KB, Klungel O, Petersen I, Sorensen HT, Dixon WG, et al. The reporting of studies conducted using observational routinely collected health data statement for pharmacoepidemiology (RECORD-PE). Bmj. 2018;363:k3532.

10. Veterans' MATES. Veterans' medicines advice and therapeutics education services. Therapeutic brief 30-know your patient's renal function-an important prescribing consideration: Department of Veterans Affairs; 2012. https://www.veteransmates.net.au/NeteransMATES/documents/module_ materials/M30_TherBrief.pdf. Accessed 12 Nov 2018.

11. Australian Medicines Handbook 2018 (online). Adelaide: Australian Medicines Handbook Pty Ltd; 2018. Available from: https:/amhonline.amh.net.au/.

12. Wongpakaran N, Wongpakaran T, Wedding D, Gwet KL. A comparison of Cohen's kappa and Gwet's AC1 when calculating inter-rater reliability coefficients: a study conducted with personality disorder samples. BMC Med Res Methodol. 2013;13:61.

13. R Core Team. R: a language and environment for statistical computing. Vienna: R Foundation for Statistical Computing; 2017. https://www.R-project.org/.

14. Khanal A, Castelino RL, Peterson GM, Jose MD. Dose adjustment guidelines for medications in patients with renal impairment: how consistent are drug information sources? Intern Med J. 2014;44(1):77-85.

15. Khanal A, Peterson GM, Castelino RL, Jose MD. Renal drug dosing recommendations: evaluation of product information for brands of the same drug. Intern Med J. 2014;44(6):591-6.

16. Jones GR. Estimating renal function for drug dosing decisions. Clin Biochem Rev. 2011;32(2):81-8.

17. Botev R, Mallie JP, Wetzels JF, Couchoud C, Schuck O. The clinician and estimation of glomerular filtration rate by creatinine-based formulas: current limitations and quo vadis. Clin J Am Soc Nephrol. 2011;6(4):937-50.

18. Miller WG, Myers GL, Ashwood ER, Killeen AA, Wang E, Thienpont LM, Siekmann L. Creatinine measurement: state of the art in accuracy and interlaboratory harmonization. Arch Pathol Lab Med. 2005;129(3):297-304.

19. Hudson JQ, Nyman HA. Use of estimated glomerular filtration rate for drug dosing in the chronic kidney disease patient. Curr Opin Nephrol Hypertens. 2011;20(5):482-91.

20. Nyman HA, Dowling TC, Hudson JQ, Peter WL, Joy MS, Nolin TD. Comparative evaluation of the Cockcroft-Gault equation and the modification of diet in renal disease (MDRD) study equation for drug dosing: an opinion of the nephrology practice and research network of the American College of Clinical Pharmacy. Pharmacotherapy. 2011;31(11):1130-44.

21. Park EJ, Wu K, Mi Z, Dong T, Lawrence JP, Ko CW, Huang SM, Zhang L, Crentsil $V$, Zhang J, et al. A systematic comparison of cockcroft-gault and modification of diet in renal disease equations for classification of kidney dysfunction and dosage adjustment. Ann Pharmacother. 2012;46(9):1174-87.

22. Hudson JQ, Nolin TD. Pragmatic use of kidney function estimates for drug dosing: the tide is turning. Adv Chronic Kidney Dis. 2018;25(1):14-20.
23. Szummer K, Evans M, Carrero JJ, Alehagen U, Dahlstrom U, Benson L, Lund LH. Comparison of the chronic kidney disease epidemiology collaboration, the modification of diet in renal disease study and the Cockcroft-Gault equation in patients with heart failure. Open Heart. 2017;4(2):e000568.

24. Laville SM, Metzger M, Stengel B, Jacquelinet C, Combe C, Fouque D, Laville M, Frimat L, Ayav C, Speyer E, et al. Evaluation of the adequacy of drug prescriptions in patients with chronic kidney disease: results from the CKDREIN cohort. Br J Clin Pharmacol. 2018;84(12):2811-23.

25. Saad R, Hallit S, Chahine B. Evaluation of renal drug dosing adjustment in chronic kidney disease patients at two university hospitals in Lebanon. Pharm. 2019;17(1):1304.

26. Solak Y, Biyik Z, Gaipov A, Kayrak M, Ciray H, Cizmecioglu A, Tonbul HZ, Turk S. Drug dose adjustment in Dialysis patients admitted in clinics other than internal medicine. Am J Ther. 2016;23(1):e68-73.

\section{Publisher's Note}

Springer Nature remains neutral with regard to jurisdictional claims in published maps and institutional affiliations.
Ready to submit your research? Choose BMC and benefit from:

- fast, convenient online submission

- thorough peer review by experienced researchers in your field

- rapid publication on acceptance

- support for research data, including large and complex data types

- gold Open Access which fosters wider collaboration and increased citations

- maximum visibility for your research: over $100 \mathrm{M}$ website views per year

At BMC, research is always in progress.

Learn more biomedcentral.com/submissions 